\title{
Effect of Personal Variables of Youths of Rajkot District on Their Health Care Awareness
}

\author{
Mohit M. Pandya* \& Dr. D. J. Bhatt**
}

\begin{abstract}
The study was designed to investigate the impact of certain socio personal variables on Health Care Awareness of youths' of Rajkot district. The sample consisted of 240 youths' (120 Male/120 Female) selected randomly from Rajkot district. Health Care Awareness scale of Dr. D. J. Bhatt and K.N. jhalodiya was used. Data were analysis by ' $F$ ' test and' $t$ ' test. Results revealed that there exists a No significant difference between the youths' socio personal variables ed. Gender, Education, Area, Age, Type of family, Family members, Education faculty and their Health Care awareness.
\end{abstract}

Keywords: Health Care Awareness and youths'

\section{INTRODUCTION}

Health care for the youth happiness, health, satisfaction, enjoy peace of mind, physical exercise, regular eating, adequate sleep, etc. should adopt identical. As defined by World Health Organization (WHO 1946), it is a "State of complete physical, mental, and social well being and not merely the absence of disease or infirmity". Youths' meaning 18 to 25 age people. The poor general state of health of Indian youths will have dramatic effects on our health care system in the future. Young people's health is often complex and requires a comprehensive, biopsychosocial approach (NSW Dept of Health, 2010). Some young people engage in risky behaviors that affect their health and therefore the majority of health problems are psychosocial. Many young people experience multiple problems. These behaviors are established as a young person and go on to become the lifestyles of adults leading to chronic health problems. Social, cultural and environmental factors are all important (Chown et al. 2004).

*Ph.D. Research Scholar, **Professor and Head Department of Psychology, Saurashtra University RajkotGujarat-India 360005.

C 2014 Pandya, Bhatt; licensee IJIP. This is an Open Access Research distributed under the terms of the Creative Commons Attribution License (http://creativecommons.org/licenses/by/2.0), which permits unrestricted use, distribution, and reproduction in any Medium, provided the original work is properly cited. 
This will be mainly due to smoking, alcohol, obesity, lack of physical activity and insufficient consumption of fruit, leading to common diseases such as diabetes, hyper- tension, myocardial infarction, stroke, renal insufficiency, osteoporosis and chronic back. “Today's unhealthily living youths will be tomorrow's chronically ill', as Dr. Walter Dorner, president of the Austrian Medical Association pointed out. This trend will not only lead to increased costs in health care, but it will also result in a lack of available manpower in the job market. As suggested by Chini, these costs should better be reallocated to preventive costs. Through successful prevention, health care costs arising from people older than 65 can be reduced significantly.

A preventive measure against such a development can be by enforcing a permanent change in the lifestyle and health-awareness of adolescents by the use of wellness management and self-observation. Such measures fit well into the description of the health continuum by Saranummi. Who emphasizes the advantage of proactive management of health and illness compared to reactive action? Saranummi also states that the provision of knowledge and tools for self-management is another important part of the health continuum. This can be achieved through the use of wellness applications that offer their end users assistance in performing selfobservation and motivate them to improve their lifestyle over a long-term period.

Young people have specific health problems and developmental needs that differ from those of children or adults: The causes of ill-health in adolescents are mostly psychosocial rather biological. Young people often engage in health risk behaviors that reflect the processes of adolescent development: experimentation and exploration, including using drugs and alcohol, sexual behavior, and other risk taking that affect their physical and mental health. The leading health related problems in the age group $12-24$ years are (AIHW, 2007).

Intensive care units (ICU's) contain complex health care situation sand area challenging area for such systems. A number of researchers have underlined this context of work as particularly relevant to the evaluation of complex tools assisting the cooperation between workers. The medium term perspective of our research is the definition of a set of requirements for the use of context-awareness tools in the ICU. 


\section{METHOD}

\section{Objective}

The main aim of this study was to investigate the impact of the personal variables of Rajkot district youths' on their Health Care Awareness.

\section{Hypotheses}

1. There is no significant difference between Health care awareness of male and female Rajkot district youths'.

2. There is no significant difference between Health care awareness and education of Rajkot district youths'.

3. There is no significant difference between Health care awareness and area of Rajkot district youths'.

4. There is no significant difference between Health care awareness and age of Rajkot district youths'.

5. There is no significant difference between Health care awareness and types of family of Rajkot district youths'.

6. There is no significant difference between Health care awareness and family members of Rajkot district youths'.

7. There is no significant difference between Health care awareness and Educational Faculty of Rajkot district youths'.

\section{Samples}

The sample size was 240 youths', comprising of 120 Male and 120 Female youths' from Rajkot district. All were aged between 18 to 25 years. The collected information can be managed carefully and more accurately.

\section{Tools}

Health care awareness Questionnaire: it was developed by Dr. D. J. Bhatt and K.N. Jhalodiya (2009), was used to measure Health Care Awareness. The questionnaire contains 40 items with True, Neutral and False response alternative. The maximum possible score is one 120 and 
minimum is 40. High score indicates high level of Health Care Awareness. The test - retest reliability coefficient is 0.89 and validity is 0.84 .

\section{RESULT AND DISCUSSION}

Table: 1 Analysis of variance based on health care awareness of youths' of Rajkot district with respect to gender, Education and Area

\begin{tabular}{|l|l|l|l|l|}
\hline Source of Variation & Sum of Square & df & $\begin{array}{l}\text { Mean Sum of } \\
\text { Square }\end{array}$ & F \\
\hline A (Gender) & 84.01 & 1 & 84.01 & $0.94 \mathrm{NS}$ \\
\hline B (Education) & 322.01 & 1 & 322.01 & $3.61 \mathrm{NS}$ \\
\hline C (Area) & 132.01 & 1 & 132.01 & $1.48 \mathrm{NS}$ \\
\hline A x B & 940.04 & 1 & 940.04 & $10.56^{*}$ \\
\hline A x C & 238.82 & 1 & 238.82 & $2.68 \mathrm{NS}$ \\
\hline B x C & 454.03 & 1 & 454.03 & $5.10^{* *}$ \\
\hline A x B x C & 1108.90 & 1 & 1108.90 & $12.46^{*}$ \\
\hline Between & 3279.84 & & & \\
\hline Within error & & 232 & & \\
\hline Total & & 239 & & \\
\hline
\end{tabular}

$\mathrm{NS}=$ Not Significant, $* \mathrm{P}<0.01 * * \mathrm{P}<0.05$

According to table No. 1 it is observed that ' $F$ ' value of Health Care Awareness of male and female Rajkot district youths' is 0.94 which exhibit No significant difference. From these results it can be concluded that male and female Rajkot district youths' differ as far as their Health Care Awareness is not concerned. It is observed from table No.1 that ' $F$ ' value of Health Care Awareness amongst level of education of youths' is 3.61 which do not exhibit significant 
difference even at a level of 0.05. ' $F$ ' value of Health Care Awareness amongst level of area of youths' is 1.48 which do not exhibit significant difference even at a level of 0.05 . Therefore, hypothesis three is accepted.

Table: 2 t-test comparison based on Health Care Awareness of Rajkot district youths' with respect to age, types of family, Family members and education faculty

\begin{tabular}{|c|c|c|c|c|c|}
\hline Variable & $\mathrm{N}$ & SD & Mean & SED & $\mathrm{t}$ \\
\hline \multicolumn{6}{|l|}{ Age } \\
\hline 18 to 21 & 105 & 9.98 & 31.17 & & \\
\hline 22 to 25 & 135 & 9.97 & 29.97 & 1.28 & $0.63 \mathrm{NS}$ \\
\hline \multicolumn{6}{|l|}{ Types of family } \\
\hline Joint Family & 165 & 10.29 & 99.48 & & \\
\hline Nuclear Family & 75 & 9.26 & 100.36 & 1.32 & $0.66 \mathrm{NS}$ \\
\hline \multicolumn{6}{|l|}{ Family members } \\
\hline 5 to below & 126 & 10.01 & 100.41 & & \\
\hline & & & 100.7 & & \\
\hline 5 to above & 114 & 9.83 & 98.56 & 1.27 & $1.45 \mathrm{NS}$ \\
\hline \multicolumn{6}{|l|}{$\begin{array}{l}\text { Education } \\
\text { faculty }\end{array}$} \\
\hline Arts/Commerce & 156 & 10.10 & 99.93 & & \\
\hline Science/All & 84 & 9.75 & 99.42 & 1.32 & $0.38 \mathrm{NS}$ \\
\hline & & & & & \\
\hline
\end{tabular}

NS = Not Significant

In order to know the difference between groups ' $t$ ' is calculated after ANOVA in present study, ' $t$ ' values on shown in table No. 2. From these findings it can be said that ' $t$ ' value of means obtained for the Health Care Awareness of 18 to 21 age and 22 to 25 age youths' is 1.28 which is not show significant. The' $t$ ' value of scores of Health Care Awareness of joint and nuclear 
family youths' is 1.32 which is also showing not significant. The ' $t$ ' value of scores of Health Care Awareness of 5 to below and 5 to above family members youths' is 1.27 which does not show significant. The ' $t$ ' value of scores of Health Care Awareness of arts/commerce and science/all faculty youths' is 1.32 . This value is not significant. Following finding support this result no statistically significant differences in relation to Health Care Awareness between Rajkot district youths'.

\section{CONCLUSION}

There is no significant found between the Health Care Awareness and personal variable gender, education and area Rajkot district youths'.

There is no significant found between the Health Care Awareness and age, types of family, family members, education faculty Rajkot district youths'.

\section{REFERENCE}

1. Andreas Holzinger, Stefan Dorner, Manuela Fodinger (2010). Chances of Increasing Youth Health Awareness through Mobile Wellness Applications. Health San Francisco Volume. 6389, Springer, P. 71-81.

2. Antonovsky, A. (1979), Health, stress and coping: New perspectives on mental and physical well-being, San Francisco.

3. Blear, C. D. (1997). Clinical health psychology: A specialty for the 21 st century. Health Psychology, 16, 411-416.

4. Donga Nanubhai (2007) "Educational Psychology" (First Edition), Saurashtra University, Rajkot.

5. Dr. Arvind shah and Dr. G. R. Joshi (2007). Health Psychology, divine publication, 1-6

6. Healy, B. (2012) Health and Human Rights, International Journal, Vol. 14, 36-38.

7. Marks, D. F. Murray, M. Evans, B. Willing, (2001) Health psychology: Theory, Research and practice, New Delhi: Sage Publications.

8. Nathalie Bricon-Souf, Conrad R. Newman (2007). Context awareness in health care: A review, international journal of medical informatics 76 (2007) 2-12

9. Sarafino, E. P. (2002). Health Psychology: Bio Psycho Social interactions, 4 Eds., New York: John Wiley and Sons.

10. Taylor, S.E. (1990). Health psychology, American Psychologist, 45(1), 40-50.

11. World Health Organization. Partners in Life Skills Education. Conclusions from a United Nations Interagency Meeting. Geneva: World Health Organization; 2001. 